\title{
EDUCAÇÃO ESPECIAL: INCLUSÃO, CURRÍCULO E DIVERSIDADE
}

André Migliori de Souza ${ }^{1}$

\begin{abstract}
Resumo. Esta pesquisa visa a investigar alguns aspectos do desenvolvimento da educação especial durante a história, como os modelos de pensamento que a abarcaram e suas mudanças de paradigma, observando o processo de inclusão que foi se estabelecendo na escola, considerando o currículo e suas adaptações durante o seu decurso. Considera-se também o olhar indispensável para a diversidade presente nos espaços escolares e como o currículo pode propiciar uma integração autêntica e mais democrática no processo ensino-aprendizagem.
\end{abstract}

Palavras-chave: Educação inclusiva; Diversidade; Currículo.

\begin{abstract}
This research aims to investigate some aspects of the development of special education during the history, such as the models of thought that embraced it and its paradigm changes, observing the inclusion process that was established in the school, considering the curriculum and its adaptations during its course. It is also considered the indispensable approach for the diversity present in the school spaces and how the curriculum can provide an authentic and more democratic integration in the teachinglearning process.
\end{abstract}

Keywords: Inclusive education; Diversity; Curriculum.

\section{Introdução}

A história da educação é marcada por uma visão excludente no sentido de não oferecer condições de igualdade nem ao acesso à escola, nem aos conteúdos por ela elencados como sendo de formação básica para o exercício da cidadania. Isso porque ao longo dos tempos pouco (ou nada) se considerou a respeito da individualidade que cada pessoa possui. Agrava-se ainda mais a situação quando a análise é feita em relação aos alunos portadores de necessidades educativas especiais.

Inicialmente, buscamos compreender as mudanças paradigmáticas que se processaram ao longo da história, especialmente em relação à visão sobre a educação especial e seus protagonistas - os alunos portadores de necessidades educativas

\footnotetext{
${ }^{1}$ Universidade do Grande Rio (UNIGRANRIO) - andremigliori@ hotmail.com
} 
especiais - considerando os modelos de pensamento que, aos poucos, foram moldando perspectivas diferentes sobre a mesma, observando os modelos clínico-médico, pedagógico e o socioantropológico.

Em seguida, observamos os propósitos de uma educação inclusiva, mas que apresenta alguns dilemas que têm sido alvo de reflexão e aprofundamento pelos especialistas. Procuramos compreender esses dilemas e quais são os questionamentos que eles podem levantar diante da realidade presente no processo ensino-aprendizagem, especialmente considerando de que maneira isso tem sido processado para garantir que a educação inclusiva se realize nos espaços escolares de modo satisfatório.

Então, abordamos a sempre polêmica questão do currículo e como ele pode se estabelecer para tornar a escola mais democrática e com conteúdos mais acessíveis, de modo particular com vistas para os alunos que apresentam necessidades educativas especiais. Assim, levando em conta toda a diversidade presente no espaço escolar, observam-se as adaptações possíveis e indispensáveis para que o currículo atenda aos alunos e apresente uma escola verdadeiramente para todos.

\section{Educação especial e suas mudanças paradigmáticas}

Durante muito tempo, a educação especial manteve-se completamente isolada em um "mundo particular", não mantendo qualquer tipo de integração com a chamada educação regular. De fato, havia uma total separação entre aqueles que apresentavam algum tipo de "deficiência" e os demais, tidos como normais. Eram-lhe, portanto, destinadas escolas específicas (especiais), que se diferenciavam das escolas regulares, com a presença, inclusive, de professores também específicos para o atendimento a esses alunos.

Nos dias de hoje, entretanto, percebemos mudanças significativas no que tange à educação especial. A sociedade cada vez mais tem exigido um maior processo de integração entre alunos especiais e alunos regulares, resultando na política de uma educação mais inclusiva - o que não se reflete única e exclusivamente no âmbito da educação, mas também no mundo trabalhista. Com isso, pretende-se "libertar" as crianças especiais dessas espécies de amarras, que as isolam em um universo de matriz separatista, numa tentativa de inseri-las numa dinâmica social moderna e agregadora. 
Beyer nos mostra que, historicamente, a escola conduzia a educação especial por uma racionalidade que ratificava a seguinte ideia:

[...] deixem os alunos (especiais) virem a nós. Assim, de diferentes escolas ou das suas famílias as crianças com deficiência, através de laudos, anamneses e histórias de vida, eram conduzidas para uma escola especial. Nesta escola concentravam-se os recursos pedagógicos necessários para sua educação (BEYER, 2010, p. 12).

Assim, com uma mudança de perspectiva a respeito da educação especial - que outrora se configurava como uma educação segregadora e que não ia ao encontro do aluno portador de necessidades especiais - concretiza-se a ideia de uma escola com o propósito de inclusão. Isso significa uma total mudança de paradigma, uma vez que o posicionamento de uma escola inclusiva é a de que a mesma seja estendida a qualquer pessoa, não impondo limites ao saber, pois não confere nenhuma distinção. Isso, sem dúvida, representa uma grande novidade, uma vez que uma escola igualitária nunca pôde ser observada ao longo da história, considerando que desde a Grécia Antiga (até épocas mais recentes) pessoas “deficientes" sempre foram descartadas da sociedade.

Importante ressaltar que apesar das escolas especiais serem consideradas por muitos como espaços educacionais que isolam o indivíduo, historicamente elas representam a primeira oportunidade de estudos para portadores de necessidades especiais, pois estes não eram absorvidos pelas escolas regulares. Por isso, possuem grande importância nesse processo de acolhida àqueles que não dispunham de um local que o acolhessem com o propósito de inserir-lhes na dinâmica do processo ensinoaprendizagem.

Porém, para Beyer as escolas especiais funcionaram como espécies de "medida paliativa e temporária", pois, dizia ele, "foram ou são 'casas de abrigo' para alunos sem casa", afirmando ainda que "casas de abrigo não são espaços de moradia permanente" (BEYER, op. cit., p. 15). Assim, revelava que elas constituíram um processo de transição, apontando que o futuro inovador (e justo) para uma educação mais moderna e associativa seria representado pelo princípio da inclusão.

\section{Dos modelos de pensamento sobre a educação especial}


A educação especial, em seu decurso histórico, apresentou modelos de pensamento que ora se sobrepunham a outros, ora se igualavam em termos de influência. Destacam-se nesse processo o pensamento médico (paradigma que apresentou predomínio durante mais tempo sobre a educação especial) e o modelo pedagógico, de onde provém a ideia de uma educação inclusiva.

O pensamento médico (também conhecido como paradigma clínico-médico) realiza sua abordagem sobre pessoas portadoras de necessidades especiais a partir da observação das mesmas e de suas causas numa perspectiva individual, restringindo-se às limitações individuais ou de origem familiar. Inclusive, muito preconceito foi observado ao longo da história da educação especial partindo de princípios próprios desse pensamento, que por muito tempo subestimou a capacidade das pessoas que apresentam determinadas deficiências e/ou necessidades especiais, afirmando por vezes que a vida de tais pessoas dar-se-ia quase que exclusivamente no interior de clínicas médicas. Nas palavras de Ross, "a predominância da abordagem clínica sobre a abordagem educacional, cumpre a exigência social de isolar as pessoas portadoras de uma condição biológico, físico e sensorial distinta para evitar a perturbação da ordem" (ROSS, 1999, p. 4).

Nesse ínterim, o modelo pedagógico se mostrava sem forças diante do pensamento médico, que focava na irregularidade do desempenho do indivíduo quando comparado àqueles que eram qualificados como "pessoas normais":

As medidas pedagógicas não podem modificar nada basicamente; elas têm a tarefa da correção, da compensação, da utilização das funções que permanecem e da suavização da área prejudicada através do procedimento curativo, educativo e terapêutico (BLEIDICK, 1981, p. 255 apud BEYER, op. cit., p. 17).

Tal hegemonia do modelo clínico-médico sobre a educação (especial) foi observada durante os séculos XIX e XX. Isso resultou na chamada "pedagogia terapêutica", que nas palavras de Beyer deu origem a "um estranho hibridismo entre educação e medicina" (BEYER, op.cit., p. 18), evidenciando a predominância do 
pensamento médico em relação à pedagogia - o que para muitos proveu uma espécie de material híbrido e/ou medianeiro entre "a medicina e a pedagogia".

Ainda se pode observar um outro modelo que apresenta também uma visão bem diferente sobre a questão da educação especial: o socioantropológico. Ele lança um olhar mais aberto e compreensivo à questão das diferenças, não considerando preceitos impositivos e/ou que julgam necessário estarem todos os indivíduos a eles submetidos, como apresenta o modelo clínico-terapêutico. Para Skliar, este modelo (socioantropológico) considera "a questão do aprofundamento dos aspectos comuns próprios da diversidade cultural" (SKLIAR, 1997, p. 11).

\section{A inclusão e seus dilemas}

O sonho de uma escola igualitária e verdadeiramente para todos encontra ainda muitas barreiras e desafios, que requerem significativas mudanças e reflexões mais profundas, para que o processo integratório de alunos portadores de necessidades educativas especiais seja efetivamente mais profícuo. Muito há no que se pensar a respeito quando se pretende pôr em prática a integração entre alunos especiais e alunos regulares.

Marchesi aponta quatro dilemas observados por Norwich (1993) a serem considerados como preponderantes para se pensar uma educação inclusiva. São eles: $o$ dilema do currículo comum, o dilema da identificação, o dilema pai-profissional e o dilema da integração, sem os quais, na opinião do autor, não se pode pensar uma boa consolidação de uma escola plenamente inclusiva (MARCHESI, 2004, p. 37-38).

1- O primeiro dilema (currículo comum) indaga sobre o conteúdo a ser aplicado: questiona se o conteúdo deve ser o mesmo a todos os alunos, inclusive aqueles que apresentam alto déficit cognitivo, ou se para estes o conteúdo deveria ser diferenciado;

2- O segundo - que trata da identificação do aluno - incide sobre a seguinte pergunta: identificar alunos com necessidades especiais é uma forma de ajudá-los no processo ensino-aprendizagem ou de torná-los "marcados" de forma negativa no contexto escolar? 
3- O terceiro dilema (pai-profissional) implica em investigar que "voz" deve ter "mais peso" na hora de decidir sobre o processo de escolarização dos alunos: a dos pais ou a dos profissionais ligados à sua educação?

4- E o último - integração - inquire sobre a maneira mais satisfatória para a aprendizagem de alunos com graves problemas cognitivos: em classes comuns ou em classes especiais, com profissionais e materiais específicos?

\section{A questão do currículo na perspectiva da inclusão}

Considerando o primeiro dilema evidenciado por Norwich, há de se supor que uma educação pautada pelo princípio da integração escolar é estabelecida a partir da implantação de um currículo comum a todos os alunos. A ideia de uma educação integrada baseia-se na propiciação de igual acesso à aprendizagem entre os pares, mesmo que sejam eles alunos portadores de necessidades especiais.

O que não se deve ser esquecido, em hipótese alguma, é que os alunos são diferentes. E aqui não tratamos de separar alunos regulares daqueles que apresentam necessidades especiais, mas referimo-nos a todos eles. A construção do saber não se processa da mesma maneira de um indivíduo para outro; o ritmo de aprendizagem de um aluno difere-se sobremaneira de outro. Por isso, muitos especialistas afirmam a necessidade de se observar a individualidade que cada aluno carrega em si, considerando esse fato quando da elaboração das estratégias educacionais. De modo particular, destacamos que essa consideração é indispensável quando pensamos nos alunos com necessidades educativas especiais, uma vez que precisam de uma educação mais harmonizada com as suas possibilidades.

A questão do currículo sempre foi muito complicada e polêmica para a educação como um todo. Afinal, definir padrões que se estabeleçam e sejam aplicados de modo a organizarem metodicamente a construção do conhecimento nos espaços escolares não asseguram o sucesso para classes homogêneas, tampouco para grupos heterogêneos. Marchesi alerta para a importância de se considerarem currículos mais equilibrados como parte de um processo facilitador para uma escola mais integradora:

Um currículo centrado fundamentalmente nos conteúdos conceituais e nos aspectos mais acadêmicos, que propõe 
sistemas de avaliação baseados na superação de um nível normativo igual para todos, lança ao fracasso os alunos com mais dificuldades para avançar nesses âmbitos. Os currículos mais equilibrados, nos quais o desenvolvimento social e pessoal também tem importância e em que a avaliação seja feita em função do progresso de cada aluno, facilitam a integração dos alunos (MARCHESI, op. cit., p. 39).

Ao se pensar um currículo, deve-se levar em consideração tanto a realidade sociocultural da escola quanto as distintas necessidades dos alunos. Em outras palavras, o currículo deve estar aberto à diversidade presente no espaço escolar, onde se possibilite aos alunos conhecer os outros de modo a se sensibilizarem às suas diferenças. Nesse contexto, é papel da escola também prover meios para que essa diversidade seja entendida como meio de aprendizagem a partir de uma troca que enriqueça a todos, permitindo aos alunos conhecer distintas maneiras de ser e de viver, promovendo-lhes virtudes como tolerância e respeito. E isso se depreende em todo o ambiente escolar, inclusive com a presença de uma educação para a diversidade presente em seu currículo.

\section{Diversidade na escola e adaptações no currículo}

Um grande desafio sempre tão presente no processo ensino-aprendizagem - e hoje mais notório do que nunca na história da educação - é a diversidade enquanto realidade em sala de aula. Grupos completamente heterogêneos; origens e culturas diferentes entre os pares; escolhas e/ou opções, filosofias e ideologias distintas entre si; necessidades básicas e de aprendizagens individualizadas por parte do corpo discente: há de se considerar uma postura de muita compreensão, com caminhos e propostas educacionais diversificadas para que a escola atinja o seu objetivo fundamental, que é pautar por uma formação capaz de desenvolver nos alunos certa capacidade intelectual através da apreensão de determinados conteúdos -, bem como oferecer subsídios para que estes estejam plenamente aptos a serem membros da sociedade em que vivem. E parte de todo esse desafio é produzir uma consciência capaz de identificar essas diferenças supracitadas, de modo a encará-las sem discriminação, e reconhecendo-as como individuais, opcionais e dignas de respeito. 
Pensar na diversidade (escolar) é pautar pela premissa de que todo aluno apresenta individualidades, e por isso necessita de tempo, espaço e abordagens pedagógicas diferentes para que seu acesso ao conhecimento seja mais satisfatório na escola. "O conceito de diversidade remete-nos ao fato de que todos os alunos têm necessidades educativas individuais próprias e específicas para ter acesso às experiências de aprendizagem necessárias à sua socialização" (BLANCO, 2004, p. 290).

Importante ressaltar, no entanto, que essa individualidade que cada aluno possui não deve ser compreendida como necessidade educativa especial. Ainda de acordo com Blanco, a individualidade do aluno, por vezes, pode ser atendida por meio de trabalhos individuais por parte do professor, que pode adotar inúmeras e distintas estratégias e materiais pedagógicos - o que não se configura em outros casos, onde tais abordagens são insuficientes e requerem alternativas pedagógicas especiais e extraordinárias (Ibidem). Nesse caso, tanto a escola quanto o currículo precisam ser adaptados para que o aluno possua um crescimento significativo.

Há uma tendência crescente de se tornarem os currículos cada vez mais flexíveis, de modo a contemplar mais amplamente a diversidade presente no espaço escolar. Flexíveis no sentido de pontuarem processos de aprendizagem menos extensos, mínimos, capazes de proporcionar a todos os alunos uma formação básica cultural, adaptando o currículo à realidade dos alunos e ao contexto sociocultural a que estão inseridos.

Torna-se preciso, então, considerar que a construção do currículo não pode esquecer a situação concreta e existencial dos educandos. A vida, o cotidiano, com seus problemas, suas possibilidades, seus limites e seus desafios; a cultura e a tradição, os valores e os princípios necessitam estar presentes no currículo da escola, deixando explícitos os seus caracteres político, histórico e cultural (ABENSUR, 2012, p. 293).

Flexibilizar o currículo "significa democratizar o poder da escolha sobre os conteúdos" (FREIRE, 2006, p. 111), atitude que tende a facilitar sua adequação a uma proposta de integração e a abraçar de modo mais justo e favorável à diversidade presente na escola. Assim, torna-se possível considerar as diferentes condições socioculturais e também as individuais dos alunos na hora de se refletir e de se 
posicionar em momentos decisórios, resultando em um currículo mais aberto e digno de atender às necessidades dos alunos inseridos no processo ensino-aprendizagem.

Nessa perspectiva de uma maior flexibilização do currículo, vislumbramos uma educação inclusiva e integradora que se estabeleça concretamente em nossa realidade escolar, que leve em consideração as necessidades educativas especiais a que alguns alunos estão dispostos, oportunizando-lhes igualdade de acesso ao conhecimento e à sua presença na sociedade, inclusive na dinâmica trabalhista futura. Desse modo, reconhecer que as aprendizagens essenciais previstas no currículo devem servir de parâmetro para uma educação igualitária, para todos os alunos. Isso também implica uma mudança paradigmática, uma vez que são necessárias adaptações capazes de viabilizarem um acesso à educação, à cultura e à aprendizagem como um todo de maneira mais democrática e mais abrangente.

\section{Considerações finais}

A educação especial tem adquirido muitos aliados com o passar do tempo, que compreendem não somente os especialistas e os pais de alunos portadores de necessidades educativas especiais, mas também a própria sociedade, que tem exigido um olhar mais atento para que uma educação inclusiva se estabeleça de maneira a atender adequadamente àqueles que se encontram inseridos no processo ensinoaprendizagem e que carecem de uma atenção diferenciada.

Os diversos modelos de pensamento sobre a educação e os alunos especiais têm se arrastado pela história, apresentando diferentes perspectivas na abordagem do assunto. No entanto, é nítida a mudança que tem se formado a respeito disso, considerando que os olhares pedagógico e socioantropológico têm se destacado nesse processo, garantindo um cuidado maior para que uma educação de excelência se configure como verdade para todos os alunos.

E ao falar de uma educação igualitária, percebemos que uma maior flexibilidade nos currículos tem sido um progresso nesse sentido, ainda que seja uma prática em construção, mas que tem fornecido elementos que asseguram à escola um cuidado maior para com a diversidade observada nos espaços escolares. Destaca-se, assim, uma 
mudança paradigmática que se lança à expectativa de melhorias concretas, com uma autêntica educação inclusiva em construção se fazendo presente no seio da sociedade.

\section{REFERÊNCIAS BIBLIOGRÁFICAS}

ABENSUR, Patrícia Lima Dubeux. Currículo: o jeito freireano de fazer. In: Revista Eletrônica de Educação, São Carlos, SP: UFSCar, v. 6, n. 2, p. 289-310, nov. 2012. Disponível em:

http://www.reveduc.ufscar.br/index.php/reveduc/article/viewFile/475/202. Acesso em 26/6/2016.

BEYER, Hugo Otto. Inclusão e avaliação na escola: de alunos com necessidades educacionais especiais. Porto Alegre: Mediação, 2010, 3 ed.

BLANCO, Rosa. A atenção à diversidade na sala de aula e as adaptações do currículo. In: COLL, César, MARCHESI, Álvaro, PALACIOS, Jesús. Desenvolvimento psicológico e educação: Transtornos do desenvolvimento e necessidades educativas especiais. Trad. Fátima Murad, 2 ed., Porto Alegre: Artmed, 2004.

FREIRE, Paulo. Pedagogia da esperança: um reencontro com a pedagogia do oprimido. 13. ed. Rio de Janeiro: Paz e Terra, 2006.

MARCHESI, Álvaro. A prática das escolas inclusivas. In: COLL, César, MARCHESI, Álvaro, PALACIOS, Jesús. Desenvolvimento psicológico e educação: Transtornos do desenvolvimento e necessidades educativas especiais. Trad. Fátima Murad, 2 ed., Porto Alegre: Artmed, 2004.

ROSS, Paulo Ricardo. A crise da educação especial: uma reflexão política e antropológica. In: Revista Educar, Curitiba, nº 15, p. 1-11, dez/1999.

SKLIAR, Carlos (org.). Educação \& Exclusão: abordagens socioantropológicas em educação especial. Porto Alegre: Mediação, 1997. 